\title{
A febre dos memes de política
}

\section{The outbreak of political memes}

\author{
Viktor Chagas \\ Universidade Federal Fluminense (PPGCOM-UFF) \\ <viktor@midia.uff.br>
}

\section{RESUMO}

A proposta deste trabalho é apresentar a dimensão teórica dos memes como chave para compreensão do processo político contemporâneo. Pautado por um duplo interesse imediato, este artigo propõe: (a) apresentar o meme como categoria capaz de lidar com problemas multifacetados na ordem do debate político; e (b) discutir o potencial do meme como artefato retórico e persuasivo. Dessa forma, buscamos tecer aproximações e distanciamentos com categorias de uso comum ao campo da Comunicação Política, algumas advindas de outras transpostas para, a publicidade, como o jingle, o slogan e a imagem. Para alcançarmos este objetivo, nos fiamos em um estudo exploratório sobre os memes políticos publicados no Twitter durante os debates presidenciais televisionados no primeiro turno das Eleições 2014. Com base nos dados coletados, empreendemos uma análise de conteúdo que procurou discutir a apropriação da linguagem dos memes pela propaganda política e as campanhas eleitorais na internet.

Palavras-chave: Comunicação política. Mídia e eleições. Memes de internet.

\begin{abstract}
This paper aim is to present the theoretical dimension of internet memes as a key to understanding the contemporary political process. Guided by an immediate double interest, this article proposes (a) to present the internet meme as a category capable of dealing with multifaceted problems in the order of political debate; and (b) to discuss the meme's potential as a rhetorical and persuasive artifact. In this way, we try to weave approximations and distances with categories of common use in the field of Political Communication, some coming from, others transposed to advertising and publicity, such as the jingle, the slogan, and, more general term impossible, the image. To achieve this goal, we set out an exploratory study of the political memes published on Twitter during the televised presidential debates in the first round of the 2014 Elections. Based on the data collected, we undertook a content analysis that sought to discuss the appropriation of the memes language by political propaganda and election campaigns on the internet.
\end{abstract}

Keywords: Political communication. Media and elections. Internet memes.

\section{Introdução}

Do ponto de vista da Comunicação Política, embora possa soar uma afirmação levemente anacrônica, os memes fazem parte da história das eleições e das estratégias de campanha e militância no Brasil republicano e no exterior há muitas décadas. Apesar de, enquanto perspectiva epistemológica, o conceito ser devedor de controversa herança da sociobiologia de meados da década de 1970, sua aplicação, como em outros casos relacionados a uma leitura historiográfica em retrospecto, não soa artificiosa. Aucontraire. O que os cientistas políticos têm tratado há tempos como categorias estanques, o conceito de meme é capaz de unificar. 
A proposta deste trabalho é apresentar a dimensão teórica dos memes como chave para compreensão do processo político contemporâneo. Pautado por um duplo interesse imediato, este artigo se propõe a (a) apresentar o meme como categoria capaz de lidar com problemas multifacetados na ordem do debate político; e (b) discutir o potencial do meme como artefato retórico e persuasivo (Milner, 2013; Huntington, 2016; Bayerl; Stoynov, 2014; Shifman, 2014). Dessa forma, buscamos tecer aproximações e distanciamentos com categorias de uso comum ao campo da Comunicação Política, algumas advindas e outras transpostas para a publicidade, como o jingle (Lourenço, 2009, 2011), o slogan (Reboul, 1975), e, termo mais generalista impossível, a imagem (Boorstin, 1992). Nossa intenção, contudo, não é reforçar a imprecisão conceitual sempre evidente quando discutidas as fronteiras epistêmicas dos estudos de memes (Jenkins e outros, 2013; Davison, 2012), nem apontar indiscriminadamente para todo e qualquer recurso propagandístico como um meme político, mas identificar os memes como um epifenômeno da comunicação política, produto da popularização do debate público e da subsequente superficialização desse mesmo debate.

Para alcançarmos este objetivo, nos fiamos em um estudo exploratório sobre os memes políticos publicados noTwitter durante os debates presidenciais televisionados no primeiro turno das Eleições 2014. Com base nos dados coletados e codificados pelo grupo de pesquisa $\operatorname{coLAB}^{1}$, procuramos discutir a apropriação da linguagem dos memes pela propaganda política e as campanhas eleitorais na internet. $\mathrm{O}$ artigo procura responder ao seguinte palíndromo:

(Q1) Pode o meme político ser compreendido como uma forma de propaganda?

(Q2) Pode a propaganda política ser interpretada como um meme?

Objetivamos ainda discutir quais as principais mudanças na propaganda eleitoral para a internet, enfatizando de modo particular as peças visuais construídas pelos comitês partidários, pelo comando de campanha, pela militância ou por grupos apócrifos, e que circularam nas mídias sociais entre os internautas. Nossas hipóteses são de que

(H1) O marketing político vem incorporando gradativamente a linguagem dos memes de internet na criação de peças publicitárias para divulgação de propostas dos candidatos ou difamação dos adversários; em sentido oposto,

(H2) Os memes políticos de caráter persuasivo atuam no sentido de fagocitar a retórica própria das campanhas para a produção e disseminação de

1 Expresso meus agradecimentos aos pesquisadores, bolsistas e voluntários do grupo de pesquisa coLAB pelo trabalho árduo sobre a codificação dos dados. Agradeço especialmente a Daniel Rios e Dandara Magalhães pela coleta e tratamento dos dados analisados nesta etapa da pesquisa. 
conteúdos que orbitam como paratextos a paisagem eleitoral. Estes conteúdos emulam um formato iconográfico e infográfico já fruto originalmente de uma adaptação do marketing ao ambiente das redes sociais online.

Para investigá-las, dividimos em cinco tópicos este artigo. No primeiro, tratamos dos estudos sobre propaganda eleitoral na internet e fora dela. Em seguida, revisitamos o conceito de meme e sua aplicação ao universo da política. No terceiro momento, apresentamos uma discussão sobre o caráter persuasivo dos memes políticos. Então, indicamos de modo mais detalhado a metodologia que temos empregado e, por fim, nossos resultados para esta etapa de pesquisa.

\section{Palavras-chaves: a propaganda política em múltiplas epistemes}

A propaganda é descrita por Boorstin (1992, p. 34-35) como uma falácia intencionalmente orientada, um apelativo juízo de valor que sobre-simplifica a realidade e inflama os ânimos. Ela obedece, dizo autor, ao desejo humano por ser despertado ou incitado por uma liderança. Boorstin contrapõe a propaganda, nesse aspecto, ao que ele denomina de pseudo-evento, um desdobramento do acontecimento, que o estende e complexifica. Entretanto, a propaganda guarda relação próxima ao pseudo-evento, quando se percebe que ambos são calcados em informações não espontâneas, "planejadas", "plantadas" ou "incitadas" para serem reproduzidas, inclusive e particularmente pelos media (Boorstin., p. 11). Isto significa dizer que a propaganda e o pseudo-evento compartilham o caráter intencional e enviesado, bem como a instrução de serem compartilhados. Tratam-se, portanto, de informações disseminadas para a obtenção de um efeito.

Ao tratar do slogan, enquanto componente da propaganda política, Olivier Reboul (1975, p. 11-13) sugere um paralelo com a concepção de Austin (1962) sobre o ato perlocutório, indicando que o impacto deste tipo de mensagem é habitualmente mais importante do que seu próprio sentido. O filósofo ainda prescreve as principais funções do slogan como sendo: (a) fazer aderir, (b) prender a atenção, e (c) resumir. O resumo, síntese ou "sobre-simplificação da experiência" é a definição corolária da propaganda em Boorstin, e também seu principal laço com a definição do sociólogo para a imagem. Nós devemos encarar a imagem, lembra Boorstin (1992, p. 185-194), como um conteúdo (a) sintético, criado para servir a um propósito (b) crível, isto é, apreensível por indivíduos que não acreditam em sua mensagem em princípio; é (c) passivo e congruente com a realidade, (d) tangível e concreto, capaz de apelar aos sentidos, (e) simplificado e (f) ambíguo, flutuando entre o sensível e o inteligível, a expectativa e a realidade.

O exemplo mais evidente sobre o potencial de condensar sinteticamente imagem e imaginário, dado por Boorstin (1992), não à toa faz referência ao 
universo do consumo. Ele cita a aspirina, o mimeógrafo e o celofane, entre outras marcas, que tiveram seus nomes associados aos seus usos. Já o slogan, comenta Reboul (1975, p. 7-8), nasce na Escócia do século XVI, em cuja tradução do gaélico se lê"grito de guerra de um clã". Por volta do século XIX, ganha contorno político, passando a denotar as divisas partidárias, e, no fim dos anos 1920, adquire seu significado publicitário atual. Na política contemporânea, o termo foi incorporado ainda na década de 1930, pela máquina de propaganda nazista, como uma fórmula estereotipada de mensagem persuasiva, uma espécie de "arma de guerra", como faz questão de advertir o filósofo.

Ambas as categorias desaguam em uma mesma foz, o rio caudaloso da política. Como estratégia de comunicação política, o slogan guarda, em relação à imagem, similaridades importantes em suas funções e também em seus efeitos. São ambas formas de "[...] comunicação unilateral, onde o destinatário nada pode senão repetir ou calar-se" (Reboul, 1975, p. 17).

Além destas duas categorias, a comunicação política é pródiga em desenvolver múltiplas epistemes para dar conta de fenômenos muito parecidos entre si. Tome-se como exemplo o jingle. Segundo Lourenço (2009, p. 207), "Podemos definir o jingle político como sendo qualquer canção com um propósito político e publicitário. Este objetivo pode ser tanto conseguir apoio e votos a um político (partido, frente ou causa) quanto criticar e diminuir a outro (...) adversário". O jingle é uma canção curta - normalmente em torno de 30 segundos a dois minutos, com algumas variações - e que procura resumir a mensagem do candidato, sua trajetória ou suas propostas para uma peça musical com letra e melodia de fácil compreensão e memorização. Popularizado no rádio dos Estados Unidos nos anos 1930, o recurso evoca o uso político do som, e da música em particular, historicamente marginalizado pela ciência política. Lourenço $(2009$, p. 3) recorda, por exemplo, do canto da Marseillaise, que inspirou a tomada da Bastilha. A relação mais óbvia, porém, nesse caso, é a do jingle com um "grito de guerra". Se tomarmos, então, a etimologia do slogan, perceberemos que, embora sua filologia possa ser divergente, a raiz conceitual encontra aproximações relevantes. Para Reboul (1975, p. 39), o slogan se define como:

\begin{abstract}
Uma fórmula concisa e marcante, facilmente repetível, polêmica e frequentemente anônima, destinada a fazer agir as massas tanto pelo seu estilo quanto pelo elemento de autojustificação, passional ou racional que ela comporta; como o poder de incitação do slogan excede sempre seu sentido explícito, o termo é mais ou menos pejorativo (Reboul, 1975, p. 39).
\end{abstract}

Ele, por sua vez, guarda paralelos com outros termos. A divisa, por exemplo, diz Reboul (1975, p. 36), conserva muitas de suas características, com 
exceção da "polêmica", pois se tornou um lugar-comum, quase um clichê. A divisa é, assim, um slogan que não convence mais, pois é visto como corriqueiro e obsoleto. Por seu turno, a norma, insiste o filósofo (Reboul, 1975, p. 32), embora objetive, tanto quanto o slogan, "provocar ou impedir" uma ação, tem em seu caráter ilocutório e performativo maior importância que os efeitos que produz - isto é, quem lhe faz uso pretende emitir alerta ou proibição através de sua própria enunciação, não pelo resultado dela. Isto é diferente do que ocorre no caso do slogan e também no da palavra de ordem. Esta última é definida (Reboul, 1975, p. 33) como "[...] uma fórmula breve, incitativa, frequentemente anônima e destinada às massas". Mas, a princípio, conquanto não se confundam na prática, estas mesmas palavras constantes da definição de Reboul (1975) poderiam ser aplicadas também ao jingle, pois este se trata de uma peça breve, incitativa, e anônima - na medida em que seus autores, como no caso do slogan e da palavra de ordem, não se sobressaem.

Em resumo, temos tratado como distintas chaves epistêmicas que conservam princípios retóricos em comum. E este fracionamento parece seguir adiante em direção às disputas políticas travadas no ambiente das mídias sociais.

O paralelo, por exemplo, entre as palavras de ordem, os slogans e as hashtags políticas é evidente. Recuero, Zago e Bastos (2014) dirão que as hashtags cumprem o papel de unificar a narrativa sobre um determinando acontecimento político, muitas vezes de forma panfletária. Rezende e Nicolau (2014), por sua vez, creditam às táticas de ciberativismo nas mídias sociais, o agrupamento de discursos em torno de uma ou de um grupo de palavras-chaves, o que contribui para que as hashtags se tornem não apenas um coletivo de experiências, mas uma campanha publicitária pela adesão em massa de novos sujeitos. Ao agruparem e exibirem experiências, que muitas vezes se consolidam na forma de experiências pessoais, as tags funcionam como recurso de propaganda ou incitação, além, é claro, de resumirem uma determinada ação. Pensar as hashtags como palavras de ordem, por exemplo, é compreender que, ao agruparem os conteúdos informacionais, elas também agrupam públicos ou constituencies, como afirma Hopke (2015) - ao propor que movimentos sociais como grupos ambientalistas têm feito uso desta prática com alguma margem de sucesso, produzindo o que a pesquisadora denomina de uma hashtaggingpolitics.

As dinâmicas de ação coletiva nas mídias sociais, contudo, embora se configurem a partir de técnicas retóricas (Huntington, 2016) - muitas vezes conjugadas ao humor (Taecharungroj; Nueangjamnong, 2015) -, são; extremamente dependentes da apropriação e do espalhamento da mensagem, de tal modo que, como um grito de guerra, o grau de sucesso ou insucesso de uma campanha baseada em uma hashtag política permanece como uma obra 
aberta e incompleta, à espera não apenas das massas que a entoarão mas do modo como o farão. Assim, utilizá-las como estratégia de propaganda política compreende em grande medida abrir mão do controle sobre os resultados da ação, o que, naturalmente, não é um efeito desejável para o comando de campanha (Stromer-Galley, 2013).

Em sentido oposto, encontram-se outros formatos de propaganda mais fechados, transpostos para o ambiente das mídias sociais ou produzidos para circulação nas redes sociais online, como peças visuais ou audiovisuais de campanha. O exemplo mais claro são os chamados pôsteres políticos online ("online political posters" ou OPP, originalmente), comuns em plataformas como Twitter, Instagram e Facebook (Lee; Campbell, 2016). Os pôsteres políticos online são, na definição dos criadores da expressão,

\footnotetext{
Imagens políticas desenhadas para ser compartilhadas pelas redes sociais digitais. São largamente empregadas por um quantitativo diverso de organizações políticas incluindo partidos menores ou majoritários em diferentes países (Lee; Campbell, 2016, p. 2).
}

Os pôsteres políticos online têm, assim, basicamente duas funções: uma, de caráter persuasivo, isto é, de comunicação com o público externo; e outra, de caráter organizacional, de comunicação com os convertidos (like-minded) e unificação dos discursos (Lee; Campbell, 2016; Milner, 2013). Descritos como peças visuais "[...] na forma de 'memes', [...] consistindo em uma fotografia de banco de imagens à qual os usuários acrescentam seus próprios slogans para (tipicamente) propor um efeito cômico" ou grafismos que reforçam aspectos de campanha, os pôsteres são uma tentativa de experimentar a capacidade de disseminação veloz e em larga escala proporcionada pela internet, através de conteúdos que "diferentemente dos memes, não foram criados para serem redesenhados pela audiência, constituindo-se como mensagens produzidas pelo partido, ainda que abertas à apropriação e manipulação" (Lee; Campbell, 2016, p. 3).

Os diferentes termos empregados pela literatura dificultam 0 reconhecimento de estruturas comuns às estratégias de comunicação política. Diante desta profusão de chaves conceituais, e da dificuldade em estabelecer consensos para o seu emprego teórico-epistemológico, como podemos compreender o meme político? Lee e Campbell (2016) nos permitem uma primeira aproximação, como destacamos anteriormente. A seguir, procuramos contextualizar os memes junto ao debate sobre a Comunicação Política. 
O meme político: empregabilidade teórica e apropriação histórica do conceito

Para aprofundarmos esta argumentação, faz-se mister reelaborarmos a categoria meme, de modo a adequarmos seu uso inclusive ao contexto anterior ao advento da internet social. Nesse sentido, ainda que nosso foco principal de análise se concentre sobre a retórica construída popularmente nas mídias sociais, a partir dos chamados memes de internet, é fundamental traçarmos um paralelo com manifestações culturais anteriores. Assim, Shifman (2014) se refere à possibilidade de que um dado indivíduo, mesmo antes do que a autora classifica como a "Era Digital", pudesse ter acesso a "manifestações meméticas", como o grafite "Kilroywashere" - ou nossos equivalentes nacionais: "Celacanto provoca maremoto", "Só Jesus expulsa demônio das pessoas" e "Quércia vem aí". Ao admitir a existência de memes anteriores à internet, a autora abre um leque de investigações científicas, que, embora levem em consideração que as novas tecnologias possam ter acelerado e multiplicado operações de recombinação e apropriação de sentidos desses memes, não conferem ao conceito limitação apriorística à sua aplicação histórica.

Conforme proposto pela pesquisadora (Shifman, 2014, p. 28), lançamos um olhar abrangente sobre as expressões de criatividade popular, a partir de numerosas remissões ao folclore político nacional: da reapropriação (e até subversão) de peças oficiais de propaganda, como "Lula-lá" ou "Meu nome é Enéas", a palavras de ordem adotadas/empregadas pela militância, como "Fora Dilma" ou "Não vai ter golpe". Sobre estes últimos, é curioso perceber a pervasividade da linguagem da internet em relação ao vernáculo do ativismo através do uso constante da hashtag como imperativo tático \#VemPraRua, \#ImpeachmentJá, \#ForaCunha, ou, mais uma vez, \#NãoVaiTerGolpe. Mas os memes não devem ser resumidos a uma gramática verbal. Algumas imagens são capazes de sintetizar/personificar um conjunto de referências sobre os políticos ou o cenário da política, e, de certo modo, recuperam as teses sobre o teatro político e a política de opinião (Gomes, 2004): o "sapo barbudo", a“Dilma Bolada", ou ainda os "coxinhas" e as "feminazis", todos são estereótipos (Lippmann, 2008), que, a bem da verdade, contribuem para, de um lado, simplificar e tornar rasas as percepções sobre a realidade, e de outro, ampliar o debate a camadas que habitualmente se mantinham apartadas da política.

Nos últimos meses, a farta produção de conteúdos gerados por internautas, especialmente vídeos, animações e imagens legendadas, tem elevado os memes à condição de importante objeto de pesquisa no campo da Comunicação Política. Já defendemos anteriormente (Chagas e outros, 2017; Chagas, 2016) que este tipo de conteúdo se inscreve em um novo gênero 
midiático e oportuniza uma experiência completamente nova de letramento político (Chagas, 2016), distante da política que leva em consideração apenas as ações formais e o processo decisório. Seja pelo humor e pela discussão pública que canalizam como sua face de maior visibilidade, seja pelo radicalismo e pela agressividade que despertam quando publicados como comentários sociais em meio ao debate online, os memes favorecem a familiarização do indivíduo com a política (Börzsei, 2013), a partir da propagação de mensagens persuasivas em um contexto de política viral e altamente segmentada em fandoms.

Mas como definir o que é um meme político?

Milner (2013) descreve os memes como artefatos simbólicos multimodais, passíveis de serem utilizados como comentário político populista, uma vez que incorporam referências da cultura popular. Tay $(2012$, p. 39) também está interessada na relação entre os conteúdos gerados por usuários (UGC) e a cultura popular de internet. Para ela, os memes são conteúdos que dependem da participação e do envolvimento de um "coletivo apaixonado", e, por isso mesmo, não podem ser planejados ou desenhados estrategicamente para uma audiência de massa, pois emergem sempre espontaneamente. Bayerl e Stoynov $(2014$, p. 4) utilizam a metáfora de um conjunto de imagens memoráveis para indicar que os memes orientados politicamente "[...] podem ser compreendidos como uma faceta da'democratização' do ativismo online, que ocorre em paralelo à 'hiper-democratização' dos registros audiovisuais para propósitos políticos". Kliger-Vilenchik e Thorson (2016) e Bennett e Segerberg (2012) definem os memes como enquadramentos (e contra-enquadramentos) em disputa, o que sugere um uso intencional desses conteúdos em contextos políticos. A conclusão semelhante chega AnXiao Mina (2013), ao se referir a memes de mudança social (social change) como conteúdos politicamente subversivos, frente ao regime totalitário chinês.

Hristova (2014, p. 266) propõe que se analise os movimentos de ocupação urbana através da metáfora do meme, iluminando a relação já intricada entre a política online e offline. Já para Makhortykh (2015), a distinção entre memes políticos e memes históricos é sutil:

\footnotetext{
Os memes históricos são explicitamente relacionados a um evento ou a uma personalidade histórica particular, e geralmente se referem a práticas de memória existentes, satirizando-as, fortalecendo-as ou propagando-as online (Makhortykh, 2015, p. 64).
}

Burroughs (2013) conceitua os memes políticos como parte de uma ecologia da mídia e uma esfera pública agonística na internet. Já Lawrance (2015), se referindo à organização fundamentalista BokoHaram como um meme, 
descreve o conceito como uma "ferramenta de referência cultural" capaz de exprimir medos e ansiedades através da repetição de imagens mentais. A ideia de uma imagem mental já aparece originalmente em Dawkins (1976), mas o modo como o conceito evoluiu, o associou permanentemente à arena midiática.

A definição mais precisa sobre o que vem ser o meme político, porém, segue sendo a de Shifman (2014, p. 120), para quem esses conteúdos “[...] participam de um debate normativo sobre como o mundo deveria ser e qual a melhor forma de alcançar este objetivo". A pesquisadora descreve, então, três funções interconectadas para os memes políticos. Segundo Shifman (2014), os memes podem operar (1) como instrumentos de persuasão ou advocacy política; (2) como ação popular; e/ou (3) como modos de expressão e discussão pública². Nós (Chagas e outros, 2017; Santos; Chagas, 2017; Chagas, 2016) temos utilizado a descrição destas três funções relatadas por Shifman (2014) como gêneros ou categorias de memes políticos, de modo que, em nossa investigação sobre os memes dos debates eleitorais em 2014, temos procurado mapear e classificar estas aparições, a fim de desenvolver uma taxonomia para pesquisas com memes de internet.

Este trabalho se propõe a aprofundar as relações entre os estudos de memes e a literatura da Comunicação Política em sua vertente mais tradicional. Guiando-nos a partir de discussões anteriores (Chagas et al., 2017), procuramos definir uma taxonomia para o tratamento de memes políticos, que, ao mesmo tempo, se baseia em propostas contemporâneas de autores da Comunicação, como Shifman (2014), Tay (2012) e Bennett e Segerberg (2012), e recupera trabalhos anteriores de cientistas políticos da década de 1990 que analisavam o HGPE na televisão (Figueiredo e outros, 1998). O resultado é uma tipologia que aprofunda a distinção incipiente de Shifman (2014) entre: (a) memes persuasivos, peças estrategicamente construídas para serem disseminadas de modo a angariar apoio a uma determinada proposta ou candidatura; (b) memes de ação popular, aqueles que se caracterizam como um conjunto de imagens que expressam um determinado comportamento ou temperamento coletivo; $\mathrm{e}$ (c) memes de discussão pública, os que se ancoram no humor e em situações de evidente incongruência na expectativa do internauta, geralmente identificados como piadas políticas e traduzidos por muitos autores (García, 2015) como uma nova roupagem da charge política e do comentário social. Naturalmente, como toda taxonomia, tratam-se tão-somente de tipos ideais, que comportam alguma sobreposição, pois um meme pode, ao mesmo tempo, se apresentar

2 Em contextos não democráticos e sob regimes totalitários, Shifmanainda admite uma quarta função adicional, denominada de subversão democrática. Para os fins deste trabalho, contudo, entendemos esta quarta função como presente e diluída entre as demais. 
como uma peça de humor e imbuir-se de uma retórica reacionária ou subversiva (Huntington, 2016; Bayerl e Stoynov, 2014). Apesar destas naturais áreas cinzas, o modelo taxonômico desenvolvido por esta pesquisa apresenta um conjunto de virtudes, entre elas, o fato de conferir um arcabouço onto-metodológico mais rigoroso (ou menos impreciso) para lidar com o objeto cientificamente, além de compatibilizar a literatura que enfatiza a relação entre política e novas tecnologias e os estudos pioneiros de mídia e eleições.

Nesse sentido, os memes políticos ocupam posição privilegiada entre os demais aparatos teóricos empregados para definir conceitualmente estratégias de comunicação política. Como conteúdos midiáticos, eles são capazes de difundir (ou propagar) mensagens persuasivas, na tentativa de convencer as massas e incitá-las à ação política. Com um discurso que realça determinados aspectos de um candidato, um movimento ou uma causa, eles procuram sintetizar pontos positivos ou satirizar pontos negativos, consolidando sua proposta retórica através da metáfora.

Em suma, definimos, de modo abrangente, os memes políticos como fórmulas discursivas ou artefatos culturais que, a partir de uma interação com seus congêneres, e através de um processo de circulação em diferentes redes sociais, são capazes de despertar ou demonstrar o engajamento político do sujeito ou ainda socializá-lo com o debate público, através de uma linguagem metafórica e orientada à construção de um enredo ou enquadramento próprios, que fazem uso, muitas vezes, de referências da cultura popular. Com base nesta interpretação, desenvolvemos uma discussão sobre os usos dos memes, especificamente na internet, como estratégia retórica empregada pelos candidatos durante a disputa eleitoral.

Memes (e virais) como forma de persuasão: a campanha presidencial brasileira em 2014

Anteriormente, Santos e Chagas (2017) trabalharam com uma categoria de memes de ação popular, que curiosamente se destacou nas análises dos primeiros debates eleitorais em 2014. A investigação se concentrou sobre fenômeno das fotografias que enquadravam aparelhos televisores transmitindo o debate em tempo real, numa experiência que remete à chamada "segunda tela", e marca um comportamento coletivo de grande vulto em meio ao debate político, ainda que não apresente com clareza um posicionamento ou sequer uma ação engajada. É, portanto, imprescindível observar com mais cautela os modos de conversação nas redes, uma vez que iniciativas em princípio 
desconectadas e desinteressadas podem conduzir a uma grave reavaliação do paradigma segundo o qual o cidadão médio não se interessa por debater política.

Ao enfatizar aqui a retórica dos memes, porém, trataremos em especial de conteúdos persuasivos, muitas vezes, ideológicos, construídos para serem disseminados como peças de campanha. Como imagens que circulam nas mídias sociais, são caracteristicamente mais "virais" do que "memes"; seu sucesso é calculado menos com base nas variações apresentadas diante do original, e mais nas replicações da peça através das redes. Há um uso intensivo de infográficos, comparações de dados entre dois ou mais políticos, e citações de candidatos durante discursos públicos, em comícios, nos debates ou em entrevistas aos meios de comunicação.

Dentre todas as formas de memes, portanto, os de caráter persuasivo são, conforme descrito por Shifman (2014, p. 124-127), aqueles que mais se aproximam da condição de peças virais. Por definição, eles se ancoram no elemento da persuasão contido em uma mensagem resumida que procura apelar ou convencer o destinatário, bem como na influência pessoal e no aspecto relacional de sua propagação. A viralidade por si mesma, pontua ainda Shifman (2014, p. 124), pode ser considerada como elemento de persuasão, à medida que expõe a opinião de outros e exerce a pressão do chamado efeito da influência social (Margetts e outros, 2013) - em particular, quando somos expostos aos indicadores de apreciação e compartilhamento de um dado conteúdo nas plataformas de mídias sociais. Em muitos casos, é difícil e pouco relevante diferenciar o meme persuasivo do conteúdo viral, pois aqueles são geralmente criados e disseminados por um grupo de elite ou agitadores que inflamam, através de suas redes, o processo. Descritos por diversos segmentos como "influenciadores", estes indivíduos ou grupos atuam no sentido de difundir uma mensagem ou um princípio do qual compactuam. E o fazem materializando - por meio de palavras, composições sonoras, grafismos ou imagens em movimento - uma síntese de suas ideias, em uma pequena peça que se utiliza de linguagem publicitária para convencer o destinatário da importância em não quebrar a corrente.

Com relação à origem do conteúdo, os memes persuasivos podem ser criados ou encomendados como publicidade patrocinada pelo partido, pelo próprio candidato, por um grupo de interesse, um cidadão em particular, ou por entidades da mídia (Shifman, 2014, p. 125). Seu processo de circulação é muito semelhante ao que Rojecki e Meraz (2016) caracterizam como "misturas de informação factícia" (no original, "factitious informations blends", FIBs) ou, em tradução livre, factoides. Para os autores, os factoides 


\begin{abstract}
Representam uma nova forma de desinformação que lembra o rumor em algum sentido, mas que é qualitativamente distinta em outros. Diferentemente do rumor, por exemplo, os FIBs não requerem um cenário psicológico de incertezas para sua disseminação. $O$ interesse do próprio partido e uma razão que o motive podem ser suficientes para espalhá-lo e sustenta-lo (Rojecki; Meraz, 2016, p. 26).
\end{abstract}

Além disso, osfactoides sedistinguem deoutrasformas de "desinformação", segundo Rojeckie Meraz (2016, p.28), porque (1) são difundidos primordialmente por agentes da elite, "empresários da opinião", ativistas individuais e "grupos quase-políticos"; (2) seu objetivo é desacreditar políticos rivais; e (3) sua origem e autenticidade não são facilmente verificáveis. Os memes persuasivos não se tratam apenas de material de campanha negativa, com o intuito de desacreditar ou difamar os adversários. Eles podem também, e na maior parte das vezes o fazem, se apresentar como propagandas simples, campanhas que destacam virtudes ou propostas dos candidatos e apelar à razão ou à emoção para pedir o voto do eleitor. Ainda assim, as características elencadas sobre os factoides políticos e sua presença ostensiva na internet, como atestam os autores, nos permitem enxergar os memes persuasivos como conteúdos difundidos por atores que conservam influência na rede e cuja origem e autenticidade não são verificáveis - de forma similar ao que ocorre com slogans e jingles políticos.

Diferentemente, porém, do que aponta a definição de Lee e Campbell (2016) sobre os pôsteres políticos online (OPPs), os memes persuasivos não são uma estratégia restrita a partidos e candidatos. Eles são também recursos empregados por eleitores individualmente ou grupos de interesse, na tentativa de alavancar uma candidatura (ou derrubar outra adversária). Lee e Campbell $(2016$, p. 3) reportam que os pôsteres constituem “[...] uma forma visual específica que atende ao esforço explícito de partidos políticos para colonizar audiências potencialmente despolitizadas, conectadas a seus apoiadores", e chamam a atençãopara ofatodequeesses materiaisvisuais podemsercompreendidoscomo umamanifestaçãocontemporânea daprofissionalizaçãodacomunicaçãopolítica.

Nosso entendimento é de que os memes persuasivos não são apenas materiais visuais - muito embora, neste estágio da pesquisa, nos concentremos sobre as imagens que circularam nas mídias sociais em 2014. Eles não se configuram materialmente apenas como pôsteres políticos, e nem tampouco têm sua origem atrelada a grupos partidários ou a candidatos necessariamente. Os OPPs são um subconjunto dos memes persuasivos, um formato possível, dentre outros, para estas peças. E possivelmente um dos formatos mais prestigiados, porquanto emulam a linguagem publicitária em seus mais diferentes elementos (Lee; Campbell, 2016). 
Assim, os OPPs são essencialmente uma peça publicitária ou brochura eletrônica produzida especificamente para o ambiente da internet e das mídias sociais por profissionais da comunicação ou assemelhados. Eles procuram aproximar a linguagem de seus materiais à dos memes de internet, tornando as peças visuais coloridas, polêmicas e atrativas ao olhar. Em contrapartida, muitos memes persuasivos criados e compartilhados por cidadãos comuns conectados ou por grupos de interesse que militam em favor de uma candidatura procuram imitar o formato dos pôsteres políticos online, empregando principalmente (a) citações diretas de candidatos ou de seus apoiadores; (b) relações de propostas ou realizações do político, ou simplesmente seu slogan junto a uma convocação para a campanha; ou (c) um infográfico ou outros grafismos que apresentem dados de pesquisas ou comparem indicadores específicos.

Há, dessa forma, um movimento de apropriação da publicidade pelos criadores de memes de internet que corre paralelamente e em sentido oposto a um movimento de apropriação da linguagem dos memes de internet pelos publicitários que atuam em campanhas eleitorais. Os memes persuasivos, segundo esta leitura, são concorrentemente origem e resposta a algumas das principais mudanças nos formatos de campanha online. No próximo capítulo deste trabalho, procuramos responder Q1 eQ2 com base na análise empreendida para os memes coletados durante as Eleições 2014.

\section{Metodologia}

Na presente etapa de pesquisa, damos continuidade ao esforço anterior de levantamento e análise de conteúdo de memes político-eleitorais mapeados durante e após os debates presidenciais televisionados em 2014 (Chagas e outros, 2017; Santos; Chagas, 2017; Chagas, 2016). Ao todo, foram coletadas aproximadamente 6 mil imagens que circularam no Twitter, das quais buscamos analisar grosso modo pouco mais da metade, o que corresponde aos conteúdos publicados na internet durante o período do primeiro turno nas Eleições 2014.

Como nas fases anteriores, tratamos a amostra a partir de um conjunto de variáveis que nos permitiu identificar os candidatos representados, o gênero e o formato dos memes, o uso de recursos narrativos específicos, e uma série de outras questões. Entre outras distinções, os materiais foram classificados como memes persuasivos, de ação popular ou de discussão pública, a cada um desses valores correspondendo ainda um conjunto de outras variáveis. Os memes persuasivos, por exemplo, em consonância com os estudos de Figueiredo e outros (1998) sobre o HGPE, tiveram também sua mensagem retórica identificada pelos codificadores. Para efeito de simplificação, contudo, 
utilizamos somente quatro subcategorias, que mesclavam a retórica e o apelo dos conteúdos analisados da seguinte maneira: (1) retórica propositiva e apelo pragmático; (2) retórica sedutora ou ameaçadora e apelo emocional; (3) retórica ético-moral e apelo ideológico; (4) retórica crítica e apelo à credibilidade da fonte.

Os dados que emergiram deste processo de codificação ${ }^{3}$ quantitativo puderam então ser cruzados, evidenciando padrões da recepção à performance dos candidatos em cada debate. Chagas e outros (2017), por exemplo, demonstraram que determinados candidatos têm maior propensão a figurarem como personagens em um tipo de meme do que outros, provavelmente em função da maneira como o público os lê. Dessa forma, os candidatos de partidos com base eleitoral mais expressiva, tidos como protagonistas da corrida eleitoral, notadamente figuram com maior evidência entre os memes do tipo persuasivo - objeto da presente investigação -, normalmente de caráter mais sério, com amplo uso de referências à mídia e a pesquisas de opinião como fontes para os dados apresentados.

Além desse primeiro mapeamento, procuramos também identificar, dentre os memes persuasivos, os materiais que correspondem à definição de Lee e Campbell (2016) para a categoria dos pôsteres políticos online (OPPs). Utilizamos como referência para esta interpretação (a) o grau de profissionalismo das peças e (b) a sua origem a partir de agentes político-partidários ou da militância. No caso de imagens que defendiam a campanha de Dilma Rousseff, por exemplo, o Muda Mais, comitê de campanha apócrifo era o principal autor das peças, seguido pela assessoria do Palácio do Planalto. Aécio Neves teve pôsteres produzidos pelo próprio comando de campanha, com a marca Aécio45, e por outras organizações, como o SomosMaisAécio e o AécioBrasil. Ao passo que Marina Silva teve a maior parte de seus pôsteres produzida e veiculada pelo partido. No caso dos memes persuasivos que não se subscrevem ao formato dos OPPs, a autoria dos materiais é de difícil identificação, e muitos deles apresentam uma qualidade bastante amadora, ainda que os materiais procurem emular a linguagem dos pôsteres profissionais.

3 No que tange a este procedimento de análise, os materiais foram sempre interpretados por dois codificadores treinados no âmbito do grupo de pesquisa coLAB, e testados para seu percentual de concordância, com índice superior a 92,9\% de acordo em todos os casos. 
Quadro 1 - Memes persuasivos

\begin{tabular}{|c|c|}
\hline Imagem 1 - OPP com aspas de Aécio Neves & $\begin{array}{l}\text { Imagem } 2 \text { - OPP com convocação de Marina } \\
\text { Silva }\end{array}$ \\
\hline 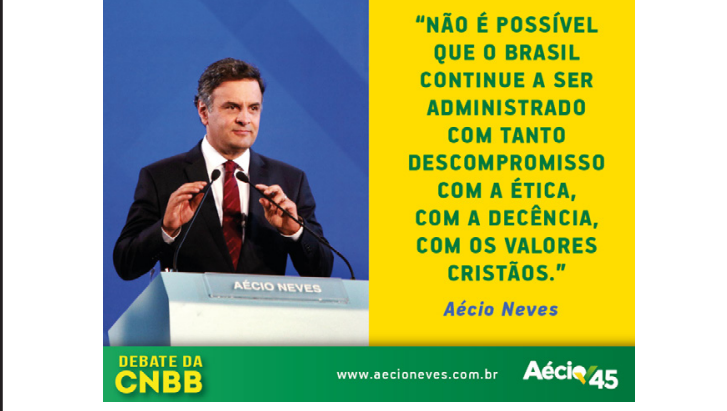 & 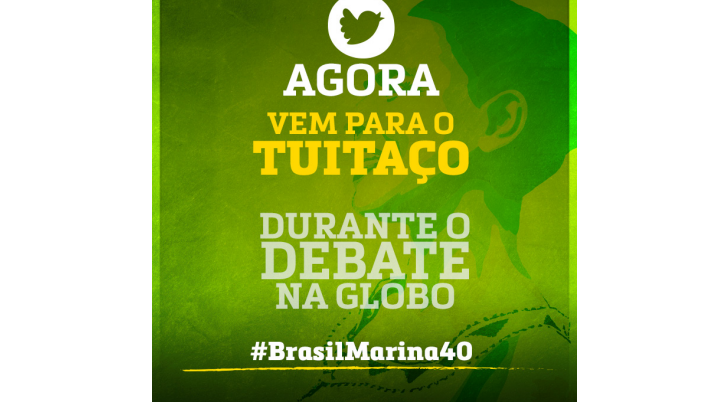 \\
\hline $\begin{array}{l}\text { Imagem } 3 \text { - OPP produzido por grupo Aé- } \\
\text { cioBrasil }\end{array}$ & $\begin{array}{l}\text { Imagem } 4 \text { - OPP com infográfico produzido } \\
\text { por grupo MudaMais }\end{array}$ \\
\hline $\begin{array}{c}\text { Horque Aécio nunca foi do PT. } \\
\text { AecoBASTL }\end{array}$ & 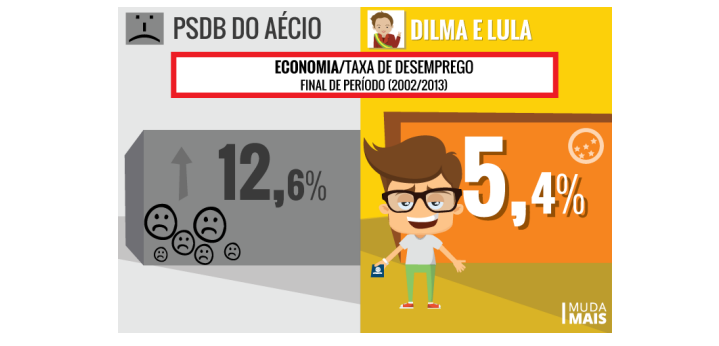 \\
\hline $\begin{array}{l}\text { Imagem } 4 \text { - OPP com aspas de Luciana Gen- } \\
\text { ro }\end{array}$ & $\begin{array}{l}\text { Imagem } 5 \text { - OPP com realizações de Dilma } \\
\text { Rousseff e Lula }\end{array}$ \\
\hline $\begin{array}{l}\text { "NÃO DUROU } 24 \\
\text { HORAS, MARINA, } \\
\text { E QUATRO TWEETS } \\
\text { DO MALAFAIA, } \\
\text { TEU COMPROMISSO } \\
\text { COM O CASAMENTO } \\
\text { CIVIL IGUALITÁRIO." }\end{array}$ & 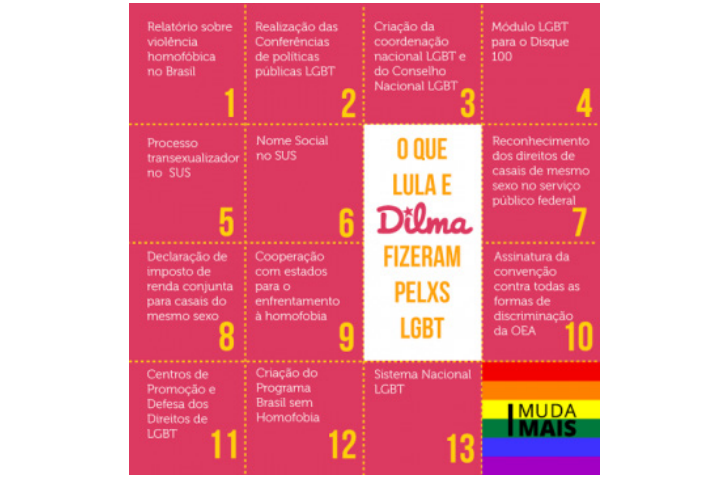 \\
\hline Imagem 6 - Meme anti-PT & Imagem 7 - Meme anti-PSDB \\
\hline 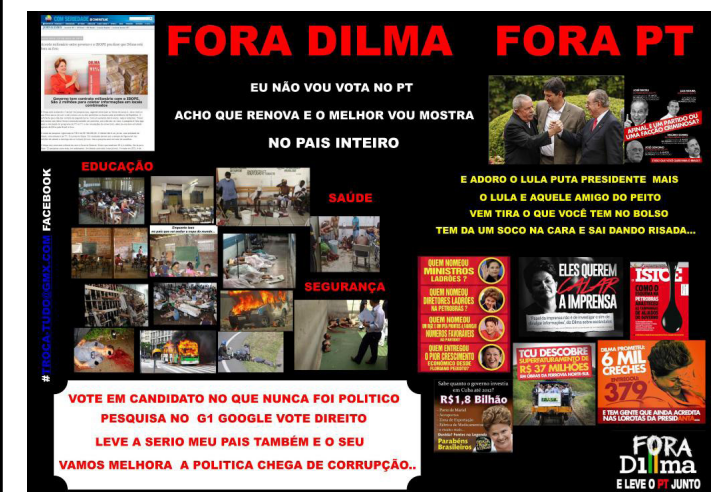 & Nos tempos do PSDB \\
\hline
\end{tabular}

Fonte: Base de dados CoLAB, a partir de imagens coletadas no Twitter. 
Por fim, buscamos ainda reconhecer padrões no que tange ao uso de citações dos candidatos ou de seus apoiadores e nos demais dados apresentados pelas imagens coletadas. Nossa expectativa foi compreender como estes memes são empregados como peças de campanha por agentes políticos e pelos internautas em geral.

\section{Resultados e discussão}

Os memes persuasivos correspondem, em média, a uma faixa em torno de $18,1 \%$ do total dos conteúdos coletados durante cada debate. Em comparação com os demais tipos, é o de presença menos marcante. Foram, por exemplo, $13,6 \%$ do total na Band; $15,6 \%$ no SBT; $25,5 \%$ na TV Aparecida; $15,8 \%$ na Record; e $21,5 \%$ na Globo. Os memes de ação popular e os de discussão pública, com relação aos mesmos debates, corresponderam a uma faixa média de 40,8\% e 31,2\%, respectivamente (cf. Quadro 2 abaixo). São, portanto, em todos os debates, o tipo de meme menos presente na amostra coletada.

\section{Quadro 2 - Tipos de memes por debate}

\begin{tabular}{|l|c|c|c|c|c|}
\hline & $\begin{array}{c}\text { Memes per- } \\
\text { suasivos }\end{array}$ & $\begin{array}{c}\text { Memes de } \\
\text { ação popular }\end{array}$ & $\begin{array}{c}\text { Memes de dis- } \\
\text { cussão pública }\end{array}$ & Outros & Total \\
\hline Band & 82 & 225 & 231 & 61 & 599 \\
\hline SBT & 75 & 157 & 202 & 44 & 478 \\
\hline TV Aparecida & 108 & 172 & 104 & 39 & 423 \\
\hline Record & 106 & 323 & 161 & 80 & 670 \\
\hline Globo & 154 & 301 & 203 & 59 & 717 \\
\hline Total & $\mathbf{5 2 5}$ & $\mathbf{1 1 7 8}$ & $\mathbf{9 0 1}$ & $\mathbf{2 8 3}$ & $\mathbf{2 8 8 7}$ \\
\hline
\end{tabular}

Fonte: COLAB.

Com relação aos candidatos, como era de se esperar, apenas os três candidatos majoritários tiveram aparições nos memes de persuasão. O resultado entre as três principais candidaturas é razoavelmente equilibrado, com exceção dos registros dos debates da Record e da Globo, em que há expressiva presença de memes do tipo persuasivo protagonizados por Dilma Rousseff (atacando-a ou defendendo-a). 
Quadro 3 - Candidatos representados em memes persuasivos por debate

\begin{tabular}{|l|c|c|c|c|c|c|}
\hline & Band & SBT & TV Aparecida & Record & Globo & Total* $^{*}$ \\
\hline Dilma Rousseff & 31 & 28 & 38 & 46 & 52 & 195 \\
\hline Aécio Neves & 38 & 29 & 30 & 20 & 12 & 129 \\
\hline Marina Silva & 11 & 20 & 20 & 23 & 13 & 87 \\
\hline Eduardo Campos & 1 & 1 & 0 & 0 & 1 & 3 \\
\hline Luciana Genro & 1 & 1 & 1 & 1 & 0 & 4 \\
\hline Pastor Everaldo & 1 & 0 & 1 & 0 & 0 & 2 \\
\hline Eduardo Jorge & 0 & 0 & 2 & 2 & 0 & 4 \\
\hline Levy Fidélix & 1 & 1 & 0 & 2 & 0 & 4 \\
\hline J. M. de Almeida & 1 & 0 & 0 & 0 & 0 & 1 \\
\hline J. M. Eymael & 0 & 0 & 0 & 0 & 0 & 0 \\
\hline Mauro lasi & 0 & 0 & 0 & 0 & 0 & 0 \\
\hline Rui C. Pimenta & 0 & 0 & 0 & 0 & 0 & 0 \\
\hline Total* & 85 & 80 & 92 & 94 & 78 & - \\
\hline
\end{tabular}

* Mais de um candidato pode ser retratado em um único meme.

Fonte: CoLAB.

No que tange à retórica dos memes persuasivos (cf. Quadro 4), tivemos uma frequência menor de peças que apresentavam propostas dos candidatos ou chamavam o eleitor à razão. Aqui, é curioso perceber que a retórica éticomoral e o apelo ideológico, em conjunto com a retórica sedutora ou ameaçadora e o apelo emocional, orientaram boa parte das análises sobre o debate público como ele se desenrolou no ambiente polarizado das mídias sociais. Mas a predominância fica por conta do apelo à credibilidade da fonte, em razão do intenso uso de dados sobre pesquisas de opinião e notícias divulgadas nos meios de comunicação tradicionais.

\section{Quadro 4 - Retórica e apelo de memes persuasivos por debate}

\begin{tabular}{|l|c|c|c|c|c|c|}
\hline & Band & $S B T$ & $\begin{array}{c}\text { TV Apare- } \\
\text { cida }\end{array}$ & Record & Globo & Total \\
\hline $\begin{array}{l}\text { Retórica propositiva e apelo } \\
\text { pragmático }\end{array}$ & 20 & 11 & 23 & 14 & 20 & 88 \\
\hline $\begin{array}{l}\text { Retórica sedutora ou ameaçado- } \\
\text { ra e apelo emocional }\end{array}$ & 12 & 22 & 30 & 34 & 44 & 142 \\
\hline $\begin{array}{l}\text { Retórica ético-moral e apelo } \\
\text { ideológico }\end{array}$ & 28 & 28 & 29 & 28 & 28 & 141 \\
\hline $\begin{array}{l}\text { Retórica crítica e apelo à credibi- } \\
\text { lidade da fonte }\end{array}$ & 22 & 13 & 24 & 29 & 57 & 145 \\
\hline Outros & 0 & 1 & 2 & 1 & 5 & 9 \\
\hline Total & 82 & 75 & 108 & 106 & 154 & 525 \\
\hline
\end{tabular}

Fonte: coLAB. 
Dos três candidatos majoritários, Dilma Rousseff é quem está mais relacionada aos memes de retórica sedutora ou ameaçadora (cf. Quadro 5). Muitos deles, flertavam com o medo com relação às candidaturas adversárias ou com os riscos associados à alta da inflação e piora dos índices econômicos do país. Já Aécio Neves e Marina Silva têm maior frequência em memes cuja retórica ético-moral é mais evidente. No caso de Aécio, isso se deve ao discurso moralizante do candidato durante o pleito. Marina, por sua vez, figura em memes críticos, com relação à sua postura ambígua sobre temas afeitos à religião e minorias LGBTT.

\section{Quadro 5 - Retórica e apelo de memes persuasivos por candidato representado}

\begin{tabular}{|l|c|c|c|}
\hline & Dilma Rousseff & Aécio Neves & Marina Silva \\
\hline $\begin{array}{l}\text { Retórica propositiva e apelo } \\
\text { pragmático }\end{array}$ & 35 & 27 & 3 \\
\hline $\begin{array}{l}\text { Retórica sedutora ou ameaça- } \\
\text { dora e apelo emocional }\end{array}$ & 62 & 33 & 29 \\
\hline $\begin{array}{l}\text { Retórica ético-moral e apelo } \\
\text { ideológico }\end{array}$ & 54 & 41 & 32 \\
\hline $\begin{array}{l}\text { Retórica crítica e apelo à credi- } \\
\text { bilidade da fonte }\end{array}$ & 40 & 25 & 22 \\
\hline Outros & 0 & 3 & 1 \\
\hline Total & 191 & 126 & 87 \\
\hline
\end{tabular}

Fonte: coLAB.

A base de dados também destaca, entre os memes persuasivos, que atendiam aos parâmetros de Lee e Campbell (2016) para serem classificados como OPPs. Nesse caso, foram 44 pôsteres publicados durante o debate na Band (53,7\% do total de memes persuasivos), 28 durante o debate no SBT (37,3\%), 32 durante o debate na TV Aparecida (29,6\%), 36 na Record (34,0\%), e 34 na Globo (22,1\%). O número elevado no primeiro debate pode refletir, de um lado o investimento das campanhas em materiais publicitários para a internet que esquentassem a disputa, de outro, o incentivo da própria emissora a uma cobertura do debate nas mídias sociais, como tem sido praxe em toda a programação da Rede Bandeirantes. Em sentido diametralmente oposto, os últimos debates, especialmente o transmitido pela Globo, apresentou um índice bastante elevado de memes de ação popular (cf. Quadro 2 novamente), o que pode supor que, naquele momento, as campanhas tenham preferido investir em conteúdos factuais e fotografias dos bastidores mais do que em peças 
de publicidade, deixando as equipes de criação já a postos para um eventual segundo turno.

A clivagem por candidaturas apresenta como dado relevante o fato de que do total de 191 memes persuasivos em que Aécio Neves figura, 54,0\% $(\mathrm{N}=68)$ são pôsteres políticos online promovidos pelo partido ou pela militância. Marina Silva aparece em 29 pôsteres (33,3\% do total de memes persuasivos). E Dilma Rousseff tem o menor índice, com uma proporção de $26,7 \%(N=51)$ entre o número de pôsteres e os memes persuasivos em que é citada. Isso significa que Dilma estrela mais conteúdos produzidos espontaneamente ou de cunho amador do que Aécio e Marina, ainda que o grupo apócrifo Muda Mais tenha tido presença relativamente marcante na divulgação de brochuras eletrônicas e infográficos citando a candidata.

Quadro 6 - Recursos empregados por OPPs conforme candidatos representados

\begin{tabular}{|l|c|c|c|}
\hline & Dilma Rousseff & Aécio Neves & Marina Silva \\
\hline $\begin{array}{l}\text { Citações diretas de candida- } \\
\text { tos ou de seus apoiadores }\end{array}$ & $35,3 \%$ & $44,1 \%$ & $37,9 \%$ \\
\hline $\begin{array}{l}\text { Relações de propostas ou } \\
\text { realizações do político, ou } \\
\text { simplesmente seu slogan } \\
\text { junto a uma convocação } \\
\text { para a campanha }\end{array}$ & $17,6 \%$ & $44,1 \%$ & $27,6 \%$ \\
\hline $\begin{array}{l}\text { Infográfico ou outros grafis- } \\
\text { mos que apresentem dados } \\
\text { de pesquisas ou comparem } \\
\text { indicadores específicos }\end{array}$ & $47,1 \%$ & $11,8 \%$ & $34,5 \%$ \\
\hline Total & $100,0 \%$ & $100,0 \%$ & $100,0 \%$ \\
\hline $\mathrm{N}$ & 51 & 68 & 29 \\
\hline
\end{tabular}

Fonte: coLAB.

A natureza desses materiais também é capaz de explicar algo sobre as decisões de campanha (cf. Quadro 6). Seguindo esta linha argumentativa, decidimos empreender também uma avaliação qualitativa dos dados, ressaltando aspectos particulares da iconografia dessas imagens, das citações e das representações dos políticos e da política contidas nelas.

Aécio e Marina figuram em muitos pôsteres que destacam trechos de suas falas durante os debates, enquanto Dilma tem maior quantidade de menções em infográficos e quadros comparativos. Dilma é também mais atacada em pôsteres (15,7\%) do que Aécio (7,3\%) ou Marina (10,3\%). Apesar desse resultado, é Marina quem mais aparece em pôsteres com citações em que se defende de ataques pessoais: 
Quem vai decidir a manutenção dos programas sociais no meu governo é a sociedade. Tenho o compromisso, sim, de manter os programas sociais, que de forma injusta e mentirosa estão dizendo que vou acabar (Marina Silva, Record).

Outro boato que está sendo dito contra nossa aliança é de que vamos enfraquecer os bancos públicos. Vamos fortalece-los. A Caixa Econômica, o BNDES e o Banco do Brasil têm uma função importante para o desenvolvimento social (Marina Silva, Record).

Marina também se apresenta, por vezes, como opção de terceira via ao país.

Não quero destruir Dilma ou Aécio! Quero poder ajudar o Brasil, que há vinte anos vive uma guerra entre azul e vermelho! (Marina Silva, Globo).

Como é natural, as citações às falas de Dilma reforçam a posição de mandatária e a estratégia de comparação com os governos anteriores do PSDB, evocando um tom que alterna entre o emocional e o pragmático para defender seu programa.

Eu pergunto à dona de casa: tem ou não tem mais empregos? Tem ou não tem mais comida na mesa? (Dilma Rousseff, Band).

Eu acredito que o povo tem memória. Ele lembra que o governo do PSDB quebrou o Brasil por três vezes. Chegamos a ter taxas de juros de $45 \%$. Nós reduzimos e hoje elas são as menores da história (Dilma Rousseff, Record).

Governar requer firmeza, coragem, posições claras e atitude firme. Não dá para improvisar (Dilma Rousseff, Record).

Aécio tem presença marcante em pôsteres cujo tom varia do apelo éticomoral ao apelo emocional, como:

Eu quero um país que gaste menos com o governo e mais com a população (Aécio Neves, Band).

Jamais transformamos, ou transformaremos, eventuais filiados que tiverem cometido qualquer crime em heróis nacionais (Aécio Neves, $S B T)$. 
Não é possível que o Brasil continue a ser administrado com tanto descompromisso com a ética, com a decência, com os valores cristãos (Aécio Neves, TV Aparecida).

Quando se defende das comparações com o Governo Fernando Henrique, o candidato faz uso de uma retórica mais pragmática.

Quem fala olhando para trás tem receio de debater o presente ou não tem nada para dizer em relação ao futuro (Aécio Neves, Band).

O Plano Real é o maior programa de transferência de renda do Brasil (Aécio Neves, SBT).

Mas, de modo geral, os trechos citados nos pôsteres reforçam a intenção do candidato em se apresentar, desde o início, como a única opção real de oposição, havendo, portanto, não apenas neste caso como em todos os demais, uma nítida confluência entre a estratégia de campanha e o uso político dos pôsteres políticos online e dos memes e virais de caráter persuasivo em sentido amplo.

Como lembra Huntington (2016), diferentes pesquisadores já se questionaram até que ponto textos visuais podem ser considerados retóricos. No caso dos pôsteres políticos online com citações dos candidatos ou de seus apoiadores destacadas, estas mensagens podem ser analiticamente evidenciadas em seu modo verbal. Em outras peças gráficas, contudo, a estratégia politicamente orientada não é menos clara (cf. Quadro 1). Nós sustentamos que os memes persuasivos permitem aos políticos não apenas disseminar seu programa como estimular a comparação com as candidaturas adversárias, ao passo que, aos cidadãos comuns conectados, esses mesmos conteúdos atuam como ferramentas de demonstração pública de afiliação e apreço a uma dada proposta ou crítica a outra.

\section{Considerações finais e limitações da investigação}

Além de, no espectro geral, procurar contribuir para compatibilizar a literatura de Comunicação Política sobre mídia e eleições com os estudos recentes sobre memes de internet e campanhas eleitorais online, nossa principal ambição com este trabalho foi de aproximar a compreensão de diferentes conceitos e categorias, até então tratados de modo esparso pelos pesquisadores. Como afirmado anteriormente, não pretendemos, com isso, unificar artificialmente todas estas ideias em torno do conceito de meme político. Entretanto, com 
este artigo, objetivamos demonstrar a aplicabilidade da categoria para os mais diferentes usos históricos e sociais.

Ademais, os dados acima, bem como os quadros que exemplificam alguns dos memes persuasivos e pôsteres políticos online apresentados neste trabalho, sugerem a autenticidade das hipóteses $\mathrm{H} 1$ e H2, conforme traçadas no início desta discussão. Para responder, então, às questões Q1 e Q2 levantadas, propomos que o meme político pode ser compreendido como uma forma de propaganda na medida em que atua com função persuasiva sobre as audiências a que se destina. Esta condição se materializa nos pôsteres políticos online, mas também nos conteúdos gerados por usuários que emulam a linguagem publicitária, indicando - sobretudo a partir de referências aos slogans dos candidatos, citações diretas às suas falas ou de seus apoiadores e dados dispostos em formatos gráficos - uma apropriação da propaganda política para o ambiente conversacional frequentado pelo cidadão comum conectado.

Por seu turno, a propaganda política pode ser interpretada como um meme se e quando produzida com finalidade específica de gerar ampla repercussão junto ao público através de uma mensagem e/ou um formato que facilite a sua reprodução. Este formato pode ser compreendido midiaticamente como os pôsteres políticos online, mas não apenas; já que os memes não se restringem às peças visuais. Mensagens que operem sobre fórmulas verbais ou não-verbais, canções musicais e padrões sonoros, ou ainda peças audiovisuais baseadas em uma estrutura que flerta com a repetição ou que estimule sua propagação de forma viral - como o jingle, o slogan etc. - podem se converter em memes políticos, desde que apropriados pelas audiências a que se destinam.

Esta pesquisa pretende ainda avançar nos paralelos traçados entre os memes e a propaganda política de tal modo a resolver algumas das limitações em sua forma atual. A primeira e mais inquietante delas diz respeito à origem dos conteúdos difundidos nas mídias sociais. Uma vez que esta origem é de difícil determinação - já que os internautas podem simplesmente copiar e renomear as imagens, aplicando sobre elas infinitas variações, e tampouco há marcas evidentes de autoria -, a distinção entre peças de propaganda desenvolvidas por agentes político-partidários ou grupos de interesse e por cidadãos que participam casualmente da política é tênue e fica restrita a uma avaliação subjetiva sobre a qualidade e o profissionalismo dessas produções. Outra limitação evidente está no fato de que, como é comum ao jogo político, a relação entre os agentes políticos oficiais e os grupos apócrifos politicamente interessados nem sempre é transparente (Santos Junior, 2016), de modo que o reconhecimento desta barreira impacta na avaliação sobre a espontaneidade ou intencionalidade de um dado meme ou viral que circula pelo ambiente das 
mídias sociais. Por último, embora o volume de dados, no presente estágio da investigação, seja grande o suficiente para nos permitir a construção de um detalhado banco de dados sobre os memes político-eleitorais em 2014, as técnicas de coleta desses dados são ainda incipientes, e dificultam a retroação, para fins comparativos, da pesquisa a contextos históricos anteriores.

À guisa de conclusão, o presente trabalho buscou testar e aperfeiçoar o framework teórico desenvolvido previamente para o estudo dos memes políticos, e apresentar importante justificativa para o olhar mais atento dos pesquisadores da Comunicação Política sobre o papel desempenhado pelos memes (e contra-memes) no contexto atual das ações conectivas (Bennet; Segerberg, 2012). Esperamos, assim, ter contribuído com um ponto de partida possível para o debate teórico sobre o tema.

\section{REFERÊNCIAS}

AUSTIN, J. L. How to do things with words. Londres: OUP, 1962.

BAYERL, P. S.; STOYNOV, L. Revenge by photoshop: meme fying police acts in public dialogue about injustice. New Media \& Society, Thousand Oaks, v. 18, n. 6, p. 1006-1026, 2014. DOI: https://doi.org/10.1177/1461444814554747.

BENNETT, W. L.; SEGERBERG, A. The logic of connective action. Information, Communication \& Society, Texas, v. 15, n. 5, p. 739-768, maio 2012. DOI: https:// doi.org/10.1080/1369118X.2012.670661.

BOORSTIN, D. The image. New York: Vintage Books, 1992.

BÖRZSEI, L. K. Political culture on the National Web: the role of political culture in online political activity and the case of Hungarian politics on Facebook. 2013.56 f. Dissertação (Masters in New Media and Digital Culture) - Utrecht University, Utrecht, Países Baixos, 2013.

BURROUGHS, B. Obama Trolling: Memes, Salute sandan Agonistic Politics in the 2012 Presidential Election. The Fibre culture Journal, New South Wales, v. 22, p. 258277, mar. 2013.

CHAGAS, Viktor; FREIRE, Fernanda; RIOS, Daniel; MAGALHÃES, Dandara. A política dos memes e os memes da política: proposta metodológica de análise de conteúdo de memes dos debates eleitorais de 2014. Intexto, Porto Alegre, v. 38, p. 173196, 2017. 
CHAGAS, Viktor. "Não tenho nada a ver com isso": cultura política, humor e intertextualidade nos memes das Eleições 2014. In: CERVI, Emerson U; MASSUCHIN, Michele G; CARVALHO, Fernanda C. de (org.) Internet e Eleições no Brasil. Curitiba: CPOP, 2016.

DAVISON, P. The language of internet memes. In: MANDIBERG, M. (Org.). The social media reader. Nova lorque: NYU Press, 2012.

DAWKINS, R. The selfish gene. Londres: OUP, 1976.

FIGUEIREDO, M. e outros. Estratégias de persuasão em eleições majoritárias: uma proposta metodológica para o estudo da propaganda política. Série Estudos, Rio de Janeiro, v. 100, p. 182-203, jul. 1998.

GARCÍA, I. G. Los memes como vehículos para la opinión pública. Versión, v. 35, p. 147159, 2015.

GOMES, W. Transformações da política na era da comunicação de massa. São Paulo: Paulus, 2004.

HOPKE, J. E. Hashtag ging politics: transnational anti-fracking movement Twitter practices. Social Media + Society, Chicago, v. 1, n. 2, p. 1-12, jul./dez. 2015.

HRISTOVA, S. Visual memes as neutralizers of political dissent. TripleC, London, v. 12, n. 1, p. 265-276, 2014.

HUNTINGTON, H. E. Pepper Spray Cop and the American Dream: using synecdoche and metaphor to unlock Internet memes' visual political rhetoric. Communication Studies, DeKalb, v. 67, n. 1, p. 77-93, nov. 2016. DOI: https://doi.org/10.1080/10 510974.2015.1087414.

JENKINS, H.; FORD, S.; GREEN, J. Spreadable media: creating value and meaning in a networked culture. Nova lorque: NYU Press, 2013.

KLIGER-VILENCHIK, N.; THORSON, K. Good citizenship as a frame contest: Kony 2012, memes, and critiques of the net worked citizen. New Media \& Society, Thousand Oaks, v. 18, n. 9, p. 1993-2011, 2016. DOI: https://doi. org/10.1177/1461444815575311.

LAWRANCE, B. Boko Haram, asylum, and memes of Africa. Hawwa, v. 13, n. 2, p. 148153, 2015. DOI: https://doi.org/10.1163/15692086-12341276.

LEE, B.; CAMPBELL, V. Looking out or turning in? Organizational ramifications of Online Political Posters on Facebook. The International Journal of Press/Politics, v. 21, n. 3, p. 313-337, 2016. DOI: https://doi.org/10.1177/1940161216645928.

LIPPMANN, W. Opinião pública. Petrópolis: Vozes, 2008. 
LOURENÇO, L. C. A música na política eleitoral: um pouco da história [do] jingle político no Brasil. In: IV ENCONTRO DA COMPOLÍTICA, 4., 2011, Rio de Janeiro. in Anais do IV Encontro da Compolítica. Rio de Janeiro: UERJ, 2011.

LOURENÇO, L. C. Jingles políticos: estratégia, cultura e memória nas eleições brasileiras. Revista Aurora, v. 4, p. 205-217, 2009.

MAKHORTYKH, M. Everything for the Lulz: historical meme sand World War II memory on Lurkomor'e. Digital Icons: Studies in Russian, Eurasian and Central European New Media, v. 13, p. 63-90, 2015.

MARGETTS, H.; JOHN, P.; HALE, S.; REISSFELDER, S. Leadership without leaders? Starters and followers in online collective action. Political Studies, p. 1-19, set. 2013. DOI: https://doi.org/10.2139/ssrn.2224187.

MILNER, R. Pop polyvocality: internet memes, public participation, and the Occupy Wall Street Movement. International Journal of Communication, Los Angeles, v. 7, p. 2357-2390, 2013.

MINA, AnXiao. Batman, Panda man and the Blind Man:a case study in social change meme sand Internet censorship in China. Journal of Visual Culture, Thousand Oaks, v. 13, n. 3, p. 359-375, dez. 2014. DOI: https://doi.org/10.1177/1470412914546576.

REBOUL, O. O slogan. São Paulo: Cultrix, 1975.

RECUERO, R.; ZAGO, G.; BASTOS, M. T. O Discurso dos \#ProtestosBR: análise de conteúdo do Twitter. Galáxia, São Paulo, v. 28, p. 199-216, 2014. DOI: https:// doi.org/10.1590/1982-25542014217911.

REZENDE, N.; NICOLAU, M. Hashtags na publicidade: a relação do \#Vemprarua \#Ogiganteacordou com as manifestações de junho/julho no Brasil. Revista Temática, João Pessoa, v. 10, n. 5, p. 219-227, maio 2014.

ROJECKI, A.; MERAZ, S. Rumors and factitious informational blends: the role of the web in speculative politics. New Media \& Society, Thousand Oaks, v. 18, n. 1, p. 2543, 2016. DOI: https://doi.org/10.1177/1461444814535724.

SANTOS, João Guilherme Bastos dos; CHAGAS, Viktor. A revolução será memetizada: engajamento e ação coletiva nos memes dos debates eleitorais em 2014. E-Compós, v. 20, n. 1, p. 1-23, 2017.

SANTOS JUNIOR, M. A. Agentes de campanha não-oficial: a rede antipetista na eleição de 2014. In: XXV ENCONTRO ANUAL DA COMPÓS, 25., 2016, Goiânia. Anais do XXV Encontro Anual da Compós. São Paulo: Compós, 2016.

SHIFMAN, L. Memes in a Digital Culture. Cambridge: The MIT Press, 2014. 
STROMER-GALLEY, J. Interação online e por que os candidatos a evitam. In: MARQUES, F. P. J. A.; SAMPAIO, R. C.; AGGIO, C. Do clique à urna: internet, redes sociais e eleições no Brasil. Salvador: EdUFBA, 2013.

TAECHARUNGROJ, V.; NUEANGJAMNONG, P. Humour 2.0: styles and types of humour and virality of memes on Facebook. Journal of Creative Communications, Thousand Oaks, v. 10, n. 3, p. 288-302, dez. 2015. DOI: https://doi. org/10.1177/0973258615614420.

TAY, G. Embracing LOLitics: popular culture, online political humor, and play. 2012. 236 f. Dissertação (Masters in Media and Communication) - University of Canterbury, Christchurch, Nova Zelândia, 2012.

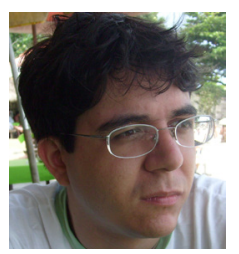

Viktor Chagas | viktor@midia.uff.br

Doutor em História, Política e Bens Culturais (Cpdoc-FGV). Professor e pesquisador do Programa de Pós-

Graduação em Comunicação da Universidade Federal Fluminense (PPGCOM-UFF).

Programa de Pós-Graduação em Comunicação da Universidade Federal Fluminense (PPGCOM-UFF)

Rua Miguel de Frias, 9 - Icaraí

24220-900 - Niterói (RJ) - Brasil 